\title{
AGENCIAMENTOS TERRITORIAIS: AS SEMIOGRAFIAS/TERRITORIALIDADES DA PRÁTICA CULTURAL/RELIGIOSA AFRO-BRASILEIRA'
}

\author{
Aureanice de Mello CORRÊE ${ }^{2}$
}

\begin{abstract}
RESUMO
O presente artigo tem como nexo de sua abordagem a compreensão do movimento de territorialização empreendido pelos povos negro-africanos na formação dos territórios-terreiros de Candomblé no Brasil por meio da prática religiosa e como esta ação, efetuada a partir dos agenciamentos territoriais, se realizou. Permitindo, portanto, à população negra a semiografia de suas tradições na reterritorialização de suas práticas culturais - material e imaterial configurando assim, a cultura afro-brasileira. Deste modo, apresento um breve panorama das estratégias/territorialidades que permitiram a elaboração de processos de resistência político-culturais. Na esteira do processo de territorialização embasado na semiografia do território original - por meio dos geossímbolos e de uma paisagem conivente constituída pela imaginação geográfica - sinalizamos para uma breve apresentação de como a base conceitual engendrada em nossas pesquisas são trabalhadas no processo de transnacionalização do Candomblé, assim como, para a elaboração de política pública visando o uso religioso de áreas de conservação ambiental.
\end{abstract}

Palavras-Chave: Agenciamento Territorial; Território-terreiro de Candomblé; Transnacionalização, Cultura e Ambiente.

\section{TERRITORY AGENCIES: THE SEMIOGRAPHIES / TERRITORIALITIES OF AFRO-BRAZILIAN CULTURAL / RELIGIOUS PRACTICE}

\begin{abstract}
The present article has as a nexus of its approach the comprehension of the territorialization movement undertaken by black African people in the formation of the Candomblés "terreiro-territory" in Brazil through the religious practice and how this action made from the territorial agencies took place. Therefore, allowing the black population to semiography of their traditions in the reterritorialization of their cultural practices - material and immaterial thus configuring Afro-Brazilian culture. In this way, I present a brief overview of the strategies / territorialities that allowed the elaboration of processes of

\footnotetext{
${ }^{1}$ Texto apresentado em palestra realizada no II Congresso Brasileiro de Organização do Espaço e XIV Seminário do Programa de Pós-Graduação (II CBOE), realizado na cidade de Rio Claro/SP, entre os dias 24 a 28 de março de 2019, intitulado "Soberania e Ciência no século XXI: a decolonialidade do saber como novo paradigma geografia?".

${ }_{2}$ Doutora em Geografia pela UFRJ; Professora Associada do Instituto de Geografia da Universidade do Estado do Rio de Janeiro (IGEOG-UERJ). Coordenadora do PROGRAMA DE ESTUDOS AVANÇADOS EM GEOGRAFIA, RELIGIÃO E CULTURA-PEAGERC/ IGEOG/SR3.
} 
political and cultural resistance. In the wake of the territorialization process, based on the semiography of the original territory - through geosymbols and a conniving landscape constituted by the geographical imagination - we signal for a brief presentation of how the conceptual basis engendered in our research are worked on the process of Candomblés transnationalization, as well as for the elaboration of public policy aiming at the religious use of environmental conservation areas.

Keywords: Territorial Agency; Candomblé Territory; Transnationalization, Culture and Environment.

\section{AGENCIAS TERRITORIAS: LAS SEMIOGRAFÍAS / TERRITORIALIDADES DE LA PRÁCTICA CULTURAL / RELIGIOSA AFRO-BRASILEÑA}

\section{RESUMEN}

El presente artículo tiene como nexo su enfoque en la comprensión del movimiento de territorialización llevado a cabo por los pueblos africanos negros en la formación de los Territorios-terreiros de Candomblé en Brasil a través de la práctica religiosa y cómo se llevó a cabo esta acción desde las agencias territoriales. Por lo tanto, permitiendo a la población negra la semiografía de sus tradiciones en la reterritorialización de sus prácticas culturales, materiales e inmateriales, configurando así la cultura afrobrasileña. De esta manera, presento una breve descripción de las estrategias / territorialidades que permitieron la elaboración de procesos de resistencia política y cultural.A raíz del proceso de territorialización basado en la semiografía del territorio original, a través de geosímbolos y un paisaje intrincado constituido por la imaginación geográfica, señalamos una breve presentación de cómo se trabaja la base conceptual engendrada en nuestra investigación en el proceso de transnacionalización de Candomblé, así como para la elaboración de políticas públicas dirigidas al uso religioso de áreas de conservación ambiental.

Palabras clave: Agencia Territorial; Territorio Candomblé; Transnacionalización, Cultura y Medio Ambiente.

\section{PRÓLOGO}

Preciso iniciar o presente texto, porém, estou com a cabeça repleta de ideias, de conjecturas, de pensamentos que povoam o meu pensar.

Me lembro, então, do momento que recebi o convite para participar do II Congresso Brasileiro de Organização do Espaço e XIV Seminário de PósGraduação em Geografia e.... A surpresa! O titulo da mesa redonda "As geografias subversivas: por uma releitura do espaço”. 
Uau!!!! Fiquei pensando que lindo. Um sentimento de alegria chegou de mansinho e me conduziu para refletir sobre a minha produção como geógrafa.

$\mathrm{Na}$ minha jornada como sujeito pensante, o mundo acadêmico tentou enquadrar o meu desejo, das coisas que queria pensar, em distintos títulos: Geografia Cultural; Geografia da Religião; Geografia quase Antropologia; Não é Geografia... Não me submeti a nenhum deles, saía com delicadeza de todos eles, sorrindo, com carinho e respeito e seguia... Escrevendo, pensando, sobre o povo preto, a cultura afro-brasileira e sua prática religiosa/cultural/social, o Candomblé, do jeito que queria, às vezes de forma poética - Geografia e Literatura - de outras, combativa, visando o enfrentamento à intolerância e racismo religioso e ambiental. Era e permanece sendo proceder assim, pois é uma felicidade quando sou recebida nos terreiros de Candomblé com carinho e consideração, benquerença mesmo, e, vejo a apropriação do meu trabalho como ferramenta de luta contra o preconceito e por seus direitos de preservar a prática cultural- religiosa afro-brasileira. Isso é muito bom.

Rizomática que sou, é coerente que não me detenha fixamente em algum ponto, a não ser para que seja apoio para partir em busca de conhecimento e para múltiplos agenciamentos. Então, Geografia Subversiva me capturou, me definiu, e senti orgulho de mim, do que penso, do que fiz, do que faço, da liberdade de pensar a Geografia sob a perspectiva do território e das territorialidades - inspirada pelas aulas de filosofia sobre Guattari e Deleuze e pela produção intelectual do geógrafo David Sack, pensando a territorialidade como uma ação humana, estratégias de lutas para enfrentamentos das adversidades, ou de constituição do novo, a reterritorialização que, me legou/lega o meu sentido de estar no mundo e viver o sonho da Utopia.

Ah! Voltemos à mesa. E que mesa redonda!!! Composta só por mulheres. Muito significativo para mim, tendo em vista que estamos atravessando um retrocesso no processo de emancipação da mulher, um tempo de misoginia, no qual, ser mulher significa ser uma "fraquejada”. Fiquei animada! O titulo da mesa redonda não me era estranho, era titulo de um livro organizado pela Joseli Maria Silva. Que felicidade, ela estava também como convidada e, como admiradora do trabalho da colega/irmã de alma fiquei honrada pela 
oportunidade de compartilhar nossas experiências acadêmicas, de vida militante das dores e conquistas de sujeitos marginalizados por uma sociedade homofóbica, racista e intolerante, rasa em compaixão e de reconhecimento da diferença do Outro, que apesar de tantos impedimentos, permanecem de cabeça erguida na luta por seus direitos. A outra colega, Amélia Nogueira, não menos querida, também pura potência de Vida, apresenta um trabalho de ponta, instigante. Enfim, estava ladeada por subversivas e isso é também muito bom!!!

Dessa forma, o que falar ou como falar, optei por iniciar saudando os Orixás, honrando a tradição afro-brasileira e a partir desta ação apresentar a minha subversão geográfica.

Kao Kabesile Xangô! (Saudamos o Rei Xangô, Rei dos Raios).

Eparrey Oyá! (Oh! Bela Oyá, Senhora dos ventos)

\section{INTRODUÇÃO}

O movimento de territorialização (compreendido pela desterritorialização / reterritorialização) ocorrido na costa oeste do continente africano desde o início do século XVI foi intenso. O modelo econômico mercantil-escravagista, constituído e garantido por uma mentalidade eurocêntrica, posicionou antigas nações africanas em conflitos internos, consequências das ações efetuadas pelo europeu no processo de apropriação de espaços outrora desconhecidos por estes, deste modo, o processo de territorialização das nações europeias, aliado ao desenvolvimento dos reinos africanos que tinham suas economias voltadas para o comércio de escravos, concordando com o Emerson Melo (2014), podem ser considerados como a máquina do desarranjo e desestruturação das economias e culturas negroafricanas.

Com o desenvolver deste processo, podemos sinalizar que o século XIX corresponde ao momento de configuração do padrão de Estado europeu na África. Neste período, os sinais do exercício de poder e controle das diferentes nações europeias sobre os povos africanos são visíveis pois, na medida em que os europeus se territorializavam ocupando novos espaços, implantavam uma nova forma de organização político-econômica e cultural diferente da local e 
estabelecia desta forma, o processo de des-re-territorialização no qual,os africanos de distintas nações - que possuíam um vínculo específico com suas cidades-reinos, seu território existencial fundamentado em valores ancestrais ficam sujeitos a sucessivas crises político-econômicas e identitárias (CORRÊA, A.M. 2004; MELO, 2014). Dessa forma, na esteira desse processo, de territorialização do Estado europeu na África com base em seus interesses políticos e econômicos, e por consequência a desterritorialização das nações africanas, foram consideradas algumas características geográficas, entretanto, os vínculos da população com a seu território/lugar foram completamente desconsiderados determinando assim, ao continente negro vivenciar, até meados do XIX, o terror da caça às mercadorias humanas para o abastecimento dos mercados negreiros no Novo Mundo.

Neste contexto, a sorte reservada para a população local foi à adaptação no modo de lidar com a nova política que se implantava e mesmo com os efeitos do fim do tráfico oriundo da efetiva territorialização do europeu, os povos africanos de distintas nações de culturas Bantos e Iorubanas tiveram que lidar com os resultados de uma economia escravagista já consolidada há quase três séculos, a qual subjugava o negro africano/afro-brasileiro, reservando para ele a condição e lugar de ser inferior, condição que não impossibilitou, não impediu as inúmeras e distintas formas de reterritorialização de tais sujeitos, constituídas com base em seus valores culturais materiais e imateriais afirmados pela prática religiosa que alicerçaram processos peculiares de resistência, em especial a constituição dos territórios-terreiros de candomblé (CORRÊA, 2004).

\section{AGENCIAMENTOS TERRITORIAIS SOB A CIRCULARIDADE CULTURAL}

O trânsito de pessoas no espaço atlântico, efetuadas desde as articulações dos africanos, de distintas nações, escravizados e confinados nos tumbeiros se intensificam e propiciam trocas culturais que passam a realizar a ação denominada como Black Atlantic e, sobre esta questão Matory (1999) 
chama atenção para o constante movimento dos povos jeje (ewe), no século XIX, entre as décadas de 1820 e 30, afirmando que

[...] os jejes brasileiros não voltavam simplesmente para a África. Eles iam e vinham fazer comércio e peregrinação, e que entre eles estavam alguns dos mais ricos afro-brasileiros que circulavam entre o Brasil, Cuba e o Golfo da Guiné (MATORY, 1999, p. 66).

Desta forma, as ações dos povos africanos na recriação e ressignificação de símbolos, signos e significantes no Novo Mundo correspondem às marcas do processo de territorialização e de reterritorialização dos povos negro-africanos na organização de suas comunidades além-mar. Neste sentido, os processos distintos de resistência que contribuíram para a formação de novas identidades e territorialidades culturalmente negras, possuem no continente africano a matriz do referencial cultural do agente negro, que se reterritorializa por meio das territorialidades estabelecidas por uma imaginação geográfica pautada em saberes ancestrais de sua cultura original engendradas com os elementos do agente dominante externo, uma característica necessária para a elaboração de estratégias para sobrevivência de tais sujeitos frente às transformações ocorridas em seu espaço-tempo. Uma prática constituída por meio de trocas culturais estabelecidas nos entremeios de fronteiras porosas de uma complexa rede, configurada a partir de uma circularidade cultural afro-atlântica (CORRÊA, 2004, MELO,2014).

Com esta direção, apesar da complexidade sobre definição de cultura, em especial sobre os povos africanos, e sua ação dialógica com distintas práticas culturais, assumimos em nosso pensar uma definição fundamentada nas observações de Claval (2003, p. 163):

A cultura aparece como um conjunto de gestos, práticas, comportamentos, técnicas, know-how, conhecimentos, regras, normas e valores herdados dos pais e da vizinhança, e adaptados através da experiência a realidades sempre mutáveis. A cultura é herança e experiência. Ela é também projeção em direção ao futuro.

Com base em tal definição e seguindo os registros historiográficos, para Melo e Corrêa (2016) o século XIX está repleto de situações que demonstram a circularidade cultural de distintas personagens negras no mundo atlântico, 
principalmente entre o Brasil e a Costa dos Escravos em diferentes períodos. Foi esse o movimento estabelecido por muitos dos fundadores dos primeiros territórios-terreiros de Candomblé da Bahia ainda no final do século XVIII a meados do XIX.

\section{O PROTO TERRITÓRIO AFRO-BRASILEIRO: ILÈ ASÈ IYÁ NASSÒ OKÁ, O TERREIRO DA CASA BRANCA}

Entre os personagens que cruzaram o Atlântico, destaca-se que, segundo as tradições do primeiro Território-terreiro de Candomblé Ilé Àsè İyá Nassò Oká, uma de suas fundadoras, possivelmente a terceira em linha de sucessão, teria feito movimento similar. Ou seja, Iyá Nassò, depois de alforriada, teria partido acompanhada de Marcelina da Silva, cujo nome de obrigação (nome que recebe ao ser iniciada no culto aos Orixás) era Obatossi e ambas eram consagradas como filhas de Xangô. Assim, Marcelina Obatossi, cujo testamento é conhecido, foi a sucessora de Iyá Nassò na Casa Branca e teria sido além de sua filha de santo, também sua prima mais jovem. Após sete anos em Ketu, elas teriam voltado acompanhadas de Maria Madalena e Claudiana, filhas de Marcelina, ou pode ser que Marcelina tivesse trazido duas crianças e chegado grávida de Maria Madalena ou Claudiana - dependendo das versões - sendo que está ultima viria a ser a mãe da Iyalorixá Senhora3. A comitiva teria voltado acompanhada por um iorubano de Oyó chamado Bamboxê, o qual iria desempenhar na sequência um papel destacado na história do axé da Casa Branca (SILVEIRA, 2006, p. 394).

No entanto, Roger Bastide (1971, p. 232) apresenta outra versão para essa passagem histórica, descrevendo que "a mãe de Iyá Nassô havia sido escrava no Brasil e depois de alforriada voltou para a África, onde a concebeu”. Anos mais tarde, Iyá Nassô ou Iyá Nassò teria vindo da Nigéria acompanhada por um homem Êssa e, por Marcelina Obatossi. Silveira (2006, p. 394) destaca que Iyá Nassò teria vindo livre para a Bahia, "com o objetivo de fundar um candomblé.

\footnotetext{
3 Mãe Senhora - Maria Bibiana do Espírito Santo (1890-1967) foi a terceira Iyálórìsá do Ilè Àse Opò Àfọnjá em Salvador, Território-terreiro que se constitui a partir do primeiro Candomblé Ile Asè Iyá Nassô Oka.

4 Ambas as ortografias são corretas.
} 
E só posteriormente é que esta última [ $\underline{O b a}$ Tosì] teria retornado à África, para aprofundar sua iniciação”.

Mesmo frente ao universo de possibilidades de interpretações e das contradições históricas já documentadas, o que destacamos é a existência de um constante fluxo de pessoas, e dentre elas, figuras importantes como as ilustres Iyálorixá Otampe Ojaro e Iyálorixá Nassò ligadas à política, comércio e ao sacerdócio religioso negro-africano, que circularam pelo mundo atlântico estabelecendo conexões e agenciamentos com redes socioculturais distintas que configuravam as rotas do atlântico negro, e que ao mesmo tempo, remodelavam os seus saberes culturais, saberes dos subjugados ou saberes dos oprimidos, mas, que resistiam no cuidado de suas tradições que se materializavam nas fissuras do espaço, ou no território usado, do cotidiano, conhecimentos fundamentais para a constituição ou ressignificações de novos territórios e consequentemente de outras territorialidades (CORREAA e MELO 2016). Deste modo, pode-se afirmar que o movimento de desterritorialização, marcado pela desestruturação de civilizações em seus diferentes aspectos: político, econômico, cultural e simbólico, não elimina a complementaridade de sua resultante: a reterritorialização, onde por meio da ação geossimbólica, uma paisagem criada por meio da imaginação geográfica inspirada na África perdida no processo de desterritorialização, permite ao grupo religioso, a elaboração de uma paisagem conivente (CORRÊE, 2002) semiografando assim, o territórioterreiro de Candomblé e estabelecendo desta forma, um arranjo espacial que se torna um padrão e uma tradição, uma territorialidade para os demais territórios-terreiros que irão se constituir seja no Brasil ou no processo de transnacionalização, que passa a ocorrer a partir dos anos 80 do século XX para Portugal e Argentina, assim como, recentemente no século XXI na elaboração de política pública que objetivava orientar o uso público religioso em área de preservação ambiental como ação de enfrentamento à intolerância religiosa que se apresentou / apresenta de forma violenta na cidade do Rio de Janeiro ( CORREAA, 2004; 2013; 2014). 


\section{PARA MELHOR EXPLICAR DO QUE ESTAMOS FALANDO E A GEOGRAFICIDADE DISSO TUDO}

Com o intuito de melhor situar como efetuamos nossa ótica para estabelecer a análise do movimento de territorialização da cultura afro-brasileira, por meio da prática religiosa Candomblé, faz-se necessário uma breve explanação sobre a orientação teórico-conceitual que sedimentou / sedimenta o nosso trabalho de pesquisa, análise e discussão sobre a temática em foco, estabelecida amplamente e ancorada nas discussões engendradas em minha tese de doutorado (2004), na qual, observamos no geógrafo BONNEMAISON (2002) o norte, em especial a concepção de territorialidade - efetuada sob uma ótica semelhante à SACK (1986) - que assume em sua perspectiva a condição de elo, entre o que denomina de fixação e mobilidade; ou seja, dos lugares e itinerários empreendidos pelos seres humanos representados por geossímbolos, que são significações culturais espaço-temporais que semiografam, sob a nossa perspectiva, identidades que constituem assim os territórios marcados pela etnicidade que por sua vez, atuam como uma verificação terrestre dos mitos que são ao mesmo tempo, fonte de poderes cósmicos e os fundamentos da organização social (BONNEMAISON, 2002; p.109). Com este sentido e consoante o citado geógrafo, o geossímbolo: "pode ser um lugar, um itinerário, uma extensão que, por razões religiosas, políticas ou culturais, aos olhos de certas pessoas e grupos étnicos assume uma dimensão simbólica que os fortalece em sua identidade (BONNEMAISON, 2002; 99 a 109)".

Desta forma, sob a nossa ótica a questão do símbolo e de seus significados, vinculado à análise espacial e à sua significação, dialoga com BAILLY (1995; p.376) ao sinalizar que a representação simbólica viabiliza a compreensão das relações de afeto e perceptos (vivência do real) entre sujeito, sociedade, o meio e as qualificações sociais coletivas, assim como, também de mitos espaciais. E, partilhando desse mesmo ponto de vista e orientado em suas considerações pelas ideias de Althusser, DI MÉO (1991; p.150) nos confirma que toda relação social inclui uma parte ideal que define a atmosfera indispensável à respiração social, isto é: “(...) um sistema de representações (imagens, mitos, ideias ou conceitos) dotados de uma existência e de um papel histórico no seio de uma dada sociedade”, que por meio da nossa perspectiva etnogeográfica, consideramos como aliados para a análise e compreensão das narrativas construídas no movimento de territorialização da prática cultural afro-brasileira no seu processo de transnacionalização, em especial, para Portugal e Argentina, 
e como sinalizamos anteriormente, ancora a projeção de uma política pública (CORRÊA, 2004; 2013; 2014).

\section{A TRANSNACIONALIZAÇÃO: O CASO DE PORTUGAL E DA ARGENTINA.}

Considerando o campo da complexidade das práticas culturais em escalas diferenciadas no atual contexto global é importante destacar fenômenos contemporâneos de transnacionalização da produção e agenciamento de subjetividades, especialmente das práticas religiosas que são vistas como subalternizadas e estigmatizadas. Essa é a temática que nos mobiliza no presente e na especificidade da compreensão das práticas culturais de matriz afro-brasileira em seu processo de transnacionalização, para Argentina e Portugal, face a uma identidade por ancestralidade que se constrói por meio de laços socioculturais históricos.

O estudo dos territórios-terreiros de Candomblé na Argentina e Portugal possui significativa importância para compreender o processo da transnacionalização da prática cultural afro-brasileira, que se territorializou no passado no Brasil e se reterritorializa na contemporaneidade fora de terra brasileira por meio da ação religiosa. Perspectiva alinhada sob a ótica do movimento de territorialização, defendida por nós em 2004 na tese de doutoramento, já sinalizado anteriormente no presente texto, quando afirmamos que o culto aos orixás efetuado na África - especialmente a iorubana - ocorreu no Brasil do século XIX a partir do proto-território, o Ile Asè Iyá Nassô Oká, o território-terreiro da Casa Branca (no bairro Vasco da Gama da cidade de Salvador na Bahia) criado por meio da materialidade e imaterialidade da cultura, ou seja, pelos seus ritos, rituais, lendas e, especialmente seu arranjo espacial na constituição territorial da prática cultural/religiosa afro-brasileira.

A descaracterização e inferiorizarão da população negro-africana e afrobrasileira pela sociedade branco-hegemônica não foram suficientes para anular os processos de agenciamentos do africano e sua subjetividade em gerenciar seus próprios processos inventivos de resistência cultural, articulações como já vimos, geradas ainda no encontro de povos distintos nos porões dos navios negreiros, os tumbeiros, que se materializaram em movimentos e estratégias 
peculiares que garantiram a sua sobrevivência durante séculos de escravização da gente negra no Novo Mundo. No entanto, atualmente as expressões de resistência, e mesmo, a prática religiosa afro-brasileira toma forma e volume, ganhando visibilidade de adeptos de suas ações, que extrapolam com a lógica de diáspora restrita entre Brasil/África, e a extensão das territorialidades passam a ocupar espaço no Velho Mundo, neste caso, Portugal que se apresenta sob a nossa perspectiva, como possível porta de entrada para a consolidação dos ritos do candomblé na Europa e na América do Sul, o caso da Argentina.

Após a realização de pesquisa de campo no Ilè Àsè Omi Ogun ,em Portugal, liderado pelo sacerdote Bàbálórìsà Jomar e por Paulo Kétu, em 2013, tornou-se possível apontar que os estudos sobre a fundação de territóriosterreiros de candomblé em Portugal é de significativa importância para compreender o processo de transnacionalização de tal prática cultural, que se reterritorializa por meio da ação religiosa, que envolve não só o exercício da fé, mas traços de uma identidade luso-afro-brasileira ou afro-brasileira lusitana em formação, fator relevante que evidencia o processo de constituição de uma identidade cultural tipicamente afroreligiosa.

Cabe mencionar que o terreiro em questão segue os mesmo moldes e formas de organização familiar das casas tradicionais de candomblé de Salvador, mais precisamente do território-terreiro do Ilé Àsè İyá Nassò Oká tido como o proto-território de um dos candomblés mais antigos da Bahia (CORRÊA, 2004) - buscando uma unidade cultural por meio da identificação visual e da reprodução de geossimbolos que demarcam o local e as estruturas simbólicas de uso ritual no interior do terreiro (CORRÊA, 2004; 2008). Acrescenta-se ainda que, o Ilè Àsè Omi Ogun, está vinculado ao terreiro do Ilè Àsè Aganjù - que descende do território-terreiro Ilè Asè Aponjá que descende por sua vez do Asè Iya Nassò Oka - liderado pelo Bàbálórìsà Ari de Jagunà, localizado em Lauro de Freitas na cidade de Salvador, e que as lideranças dos terreiros em Portugal estão em constante conexão com sua matriz religiosa, meio necessário para garantir a legitimidade de sua origem e o reconhecimento de sua prática cultural (CORRÊA, 2015; CORRÊA, e CORRÊA, 2019), pois, como se diz no interior dos terreiros de candomblé, "se conhece o fruto pela 
raiz”. No mais, o Bàbálórìsà Jomar de Ogun é responsável pela fundação do primeiro órgão de reconhecimento das instituições praticantes dos cultos afroreligiosos em Portugal, a Associação Nacional do Culto Afro-brasileiro. Tais apontamentos se fazem pertinentes, pois coloca em evidência a existência de uma rede, que coloca a Europa, continente responsável pela expropriação cultural da população negra e ameríndia no passado colonial, como mais um lugar de possíveis agenciamentos territoriais tipicamente negros que possuem sua origem em processos específicos de resistência, que por ironia, fora gerado para emancipar os povos negros frente à economia escravagista estabelecida pelas diversas nações do Velho Mundo, e dentre elas a própria coroa portuguesa.

Outro fator de extrema relevância que podemos sinalizar é que a existência de terreiros de candomblé ou a própria existência de um órgão ou instituição que regule suas práticas, não garante a seguridade do ato ritual (CORRÊA, 2014). Neste sentido, na entrevista informal com os interlocutores Bàbálórìsà Jomar e Paulo Kétu sobre a questão de intolerância religiosa registramos que os entrevistados não haviam vivenciado tal situação, no entanto, ambos afirmaram não possuir liberdade para trajar roupas e fios de contas típicos do candomblé nas ruas, o que nos remete ao questionamento da existência de tal prática. Assim sendo, vale enfatizar que ainda são incipientes se não raros os estudos sobre os terreiros de candomblé em Portugal. No entanto, é possível notar que os processos de agenciamentos territoriais que se configuraram no Atlântico Negro ainda estão em movimento, pois novas conexões estão sendo configuradas - sob um processo contínuo - do movimento de territorialização (CORRÊA, 2004; 2008; 2014) que coloca a prática religiosa do Candomblé rumo a transnacionalização de suas práticas rituais.

Concordando com Frigério $(1989$; 1997), podemos afirmar que se o transnacionalismo realizado pelas ações hegemônicas das elites é homogeneizador, em contrapartida, o que é engendrado pelas camadas populares é realizado em espaços múltiplos, e em muitos casos produto do movimento de pessoas através das fronteiras, implicando assim, em um processo de transnacionalização de práticas culturais que possui sua origem no processo migratório articulado com a formação de uma comunidade 
transmigrante, ou seja, de imigrantes que desenvolvem e mantêm relações de distintas qualificações - familiares, sociais, econômicas, políticas e religiosas que transcendem as fronteiras, unindo dessa forma, seu país de origem ao país para o qual migraram (CORRÊA, 2008).

Entretanto, podemos também observar outro movimento de transnacionalização de elementos culturais, que não se origina no movimento formador da comunidade transmigrante acima enunciado, mas, que é efetuado pelos - que vamos nominar de "promotores culturais" - professores de capoeira, samba, dança de matriz africana, sacerdotes e adeptos das práticas religiosas de matriz africana como o Candomblé e a Umbanda - que após um período de tempo de convivência despertam o interesse de pessoas no país que os recebe, efetuando relações socioculturais, que por fim agregam, pela circularidade cultural, uma nova compreensão de mundo, que influi em suas práticas cotidianas.

No caso da Argentina e o processo de transnacionalização da prática cultural afro-brasileira, Frigério (1997) nos aponta a atuação dos promotores culturais, como um canal facilitador, especialmente para os sacerdotes das religiões afro-brasileiras, do Candomblé e da Umbanda. Esse processo também ocorre em Portugal, sendo que, no caso português, a influência foi operada por meio das novelas televisivas brasileiras, realizando dessa forma, a transnacionalização em tela (PORDEUS JR., 2009).

Sendo assim, diante do exposto até aqui podemos afirmar a relevância do trabalho de campo - sob a perspectiva da etnogeografia (CLAVAL, 2012) - como possibilidade de respostas aos questionamentos enunciados no trabalho de pesquisa, como também, estabelecer condições de análise sobre esse novo território, sobretudo com visitas de reconhecimento, tendo em vista a reserva com que professam o seu direito de crença religiosa, demanda um convívio estreito para que os religiosos estabeleçam laços de confiança com a pesquisadora e com os propósitos da pesquisa. Ou seja, para que possamos compreender o território por meio do(s) olhar(es) com que os sujeitos o percebem, faz-se necessário o uso de ferramentas, técnicas e métodos de pesquisa mais flexíveis, abertos e dialógicos fundamentados em metodologias 
que são adjetivadas pelo seu caráter étnico. Portanto, a pesquisa de campo materializa o momento de diálogo e participação com os sujeitos investigados, os quais durante o processo de aproximação e da ação dialógica terão condições de nos apresentar e relatar como percebem seu território semiografado por suas crenças e tradições, seus anseios e angústias e conflitos inter-religiosos e ambientalista, suas territorialidades-estratégias de re- existência.

\section{CULTURA E AMBIENTE}

Continuando com nossa curiosidade acadêmica e tendo em vista que a Natureza é o maior bem simbólico da prática religiosa do Candomblé (constantemente afirmado pelos religiosos de matriz afro-brasileira, com as sentenças "o orixá é natureza", "kosi ewe kosi orixá" - sem folha sem orixá) como é resolvida a questão das oferendas/presentes aos orixás que necessitam serem entregues nas praias, rios e matas? E os usos de espaços urbanos públicos, ou seja, as encruzilhadas, praças e jardins, estradas de ferro? Isto é, geossímbolos para o povo de santo, para o povo do Candomblé, pois as oferendas são feitas nestes locais, tendo em vista que, para a tradição dessas práticas religiosas estes são geossimbólicamente significados pelos religiosos como locais propiciadores do acontecimento sagrado, que ao serem louvados com cantos ou elocuções e performances ritualísticas se transformam em cosmolocalidades. Portanto, como estão sendo resolvidas essas questões que envolvem os usos de espaços públicos diante da lei ambiental?

São indagações importantes, até porque são estas ações que fazem parte do ritual religioso e que compõe o processo identitário da prática cultural/religiosa do Candomblé. Mas, infelizmente suscitam naquele que não a professa e não domina os fundamentos dessa tradição religiosa, a repugnância, o preconceito e a intolerância, estabelecendo desta forma o conflito e, por muitas vezes, o desrespeito ao direito constitucional, o de liberdade religiosa e da prática dos rituais inerentes à sua religiosidade.

\section{A prática cultural, ponte que viabiliza a relação sócioespacial}

Transformações de cunho cultural, político e econômico, desde meados da década de 1970 vem movimentando o cenário mundial de maneira 
avassaladora e, onde a prática cultural se estabeleceu como uma ponte que viabiliza a relação do ser humano e da sociedade com o espaço (CORRÊA, 2014). Essa relação apresenta-se em uma mesma e complexa realidade, onde a função social e a função simbólica engendram a distinção e a correlação entre o espaço social - o espaço produzido e concebido em termos de organização e produção - e o espaço cultural (CORRÊA, 2004), sendo que este último, consoante o geógrafo Bonnemaison (2002), é definido como o espaço onde a vida é efetuada a partir da significação e da relação simbólica engendrada pela materialidade e imaterialidade da cultura.

Nesse sentido, quando observamos no território-terreiro de Candomblé, na sua paisagem conivente, a casa principal, denominado de barracão, significa o palácio do rei, a casa dos orixás - ou de forma mais contrita espacialmente, como quarto de santo - representa um reino, isto é, rememora que cada cidadereino, em especial na África iorubana, estava sob o domínio e proteção de um determinado Orixá.

Como exemplo, a cidade-reino de Oyó, sob a proteção de Xangô que exercia a função de centro do poder político para os iorubanos, no período das guerras entre nações inimigas, foi destruída e se reterritorializa em outra localidade como a Nova Oyó por meio da ação geossimbólica, demonstrando assim, que já possuíam a experiência de reconstituição de seu território via uma imaginação geográfica e da significação de locais, rios, cachoeiras vegetação, rochas, solo, como sagrados. É essa experiência que se recupera no Brasil no território-terreiro Ile Asè Iyá Nassò Oka (Casa Branca), por intermédio da materialidade da cultura, em suas edificações significadas como os reinos de seus Orixás protetores e pela imaterialidade da cultura no Xirê, a roda formada em sentido horário em torno do ponto central do Barracão, onde está assentado (enterrado) os fundamentos sagrados e cada Orixá é louvado por meio da dança, canto e gestos, convidando para a festa, a celebração de sua presença no corpo dos iniciados e da África perdida, no entanto, viva, forte e resistente.

Assim, ancorados na base conceitual apresentada ao longo do presente texto, avançamos para pensar a questão ambiental, a partir do projeto de uma política pública para uso público religioso em área protegida por lei, proposta 
pela Superintendência de Educação Ambiental da Secretaria do Ambiente, por meio da parceria com a Universidade do Estado do Rio de Janeiro no exercício de sua ação extensionista e de pesquisa. O título do projeto sob a minha coordenação representando a UERJ foi “Espaço Sagrado da curva do S”, que está localizado no Parque Nacional da Tijuca- PNT e se justificou o uso do termo espaço e não território porque como se tratava de uma ação do poder público e este é laico, não era correto delimitar a área somente para a ação das religiões de matriz africana.

É certo que o que nos motivou a pensar o projeto foi a questão de que são as práticas religiosas de matriz africana as acusadas de poluidoras do ambiente e que, diante do movimento de intolerância religiosa que se fortalecia na cidade do Rio de Janeiro, também passam a ser demonizadas, estando seus praticantes sujeitos às ações de extrema violência, como espancamento físico e/ou ameaça de morte.

Enfim, com a ajuda de Iyalorixás, Babalorixás, Ekedys, Babalawo, filhos de santo da Umbanda e do Candomblé e dos próprios orixás (pois estes falavam o que queriam por meio do jogo de Búzios e pelo Opelè de Ifá), ambientalistas vinculados ao PNT e à academia, como também arquitetos e, partindo da base conceitual explicitada no presente texto e fruto da tese de doutorado e da análise formulada para compreensão do terreiro de Candomblé sob a ótica da geografia e da prática cultural, estabelecemos uma ação dialógica horizontal e constituímos um arranjo espacial, no qual, a paisagem conivente marcada especialmente pelos geossímbolos apontados pelos religiosos foi semiografada, respeitando em sua arquitetura a preservação ambiental por meio da perspectiva da Educação Ambiental. Trabalhamos durante quatro anos, visitamos vários territórios-terreiros de distintas nações, dialogamos com os ciganos e outras religiões/práticas culturais que possuem na Natureza um bem simbólico para efeito de seus rituais.

Tivemos muito êxito, avançamos em nossos objetivos e quando estava prestes à plena realização do projeto fomos surpreendidos com a exoneração do Secretário do Ambiente, e por consequência pela mudança de propósito do governo estadual. Em 2014 o projeto encerrou, o espaço Sagrado foi 
abandonado pelo poder público. Mas, subversivos que somos, plantamos a semente. A primavera há de chegar...

\section{CONSIDERAÇÕES FINAIS}

Conforme apontado, as influências dos povos africanos no mundo atlântico não se limitaram à recriação e ressignificação de símbolos, signos e significantes apenas no Novo Mundo. As marcas do processo de des-reterritorialização de tais sujeitos continuam em movimento nas diversas regiões do Atlântico Negro. A presença de territórios-terreiros de Candomblé no Velho Mundo e na América do Sul evidencia que as antigas práticas religiosas de origem africana e afro-brasileira, cederam lugar para a multiculturalidade de processos distintos de resistência que contribuíram para a formação de novas identidades e territorialidades, que ocupam espaço em Portugal e na Argentina e nas questões ambientais. De forma que, as novas territorialidades-estratégias passem a atuar na discussão para resolução de conflitos, nos quais, estão envolvidas questões de cunho racista, de intolerância religiosa, de estranhamento da prática do diferente das ações hegemônicas. No entanto, a origem recente de tal fenômeno, nos coloca diante das seguintes indagações: como se processa o diálogo de subjetividades face às fronteiras urbanas de regulação formal de espaços de ritualização da prática cultural religiosa? É um novo candomblé, quais são os referenciais e agenciamentos que constituem tal movimento de reterritorialização? Novos cultos ou rituais serão ou já foram incorporados? Em suma, como estão e serão resolvidas essas questões? Parte destas questões foram abordadas e discutidas durante o projeto sobre o Espaço Sagrado da curva do S no PNT, e parcialmente resolvidas junto aos religiosos que formularam um documento, no qual, orientam seus pares para o uso religioso e a conservação do Ambiente. Já as outras questões ficaram em aberto, ainda sem respostas. São processos em curso, tanto aqui no Brasil assim como, na transnacionalização da prática do Candomblé para Portugal e Argentina.

Enfim, continuo buscando subversivamente pensar, pesquisar sobre a nossa sociedade. Em tempos tão complicados, de discursos de ódio, de avanços de uma extrema direita calcada em princípios religiosos retrógrados só posso 
tentar encerrar com um fragmento de poesia para amenizar a angústia do futuro incerto. Então...

Não serei o poeta de um mundo caduco.

Também não cantarei o mundo futuro.

Estou preso à vida e olho meus companheiros.

Estão taciturnos, mas nutrem grandes esperanças,

Entre eles, considero a enorme realidade.

O presente é tão grande, não nos afastemos,

Não nos afastemos muito, vamos de mãos dadas...

Mãos dadas, titulo do poema de Carlos Drummond de Andrade do livro Sentimento do Mundo de 1940 reeditado pela Editora Record. É um norte para a compreensão e a crítica ao sofrimento e a desigualdade no Mundo. Sinaliza para a necessidade imperiosa de solidariedade e de esperança, a luz acesa no fim do túnel. Tão atual. Por isso resolvi falar dele no fim da minha apresentação na mesa-redonda sobre Geografias Subversivas e do presente texto que nos remete à ela. É um convite fraterno, pleno de potência de Vida para continuarmos subversivamente caminhando de mãos dadas.

Axé, Kaò Kabesile, Eparrey Oyà!!!!

\section{REFERÊNCIAS}

BASTIDE, R. As religiões africanas no Brasil: contribuição a uma sociologia das interpretações de civilizações (2 vols.). São Paulo: Livraria Pioneira Editora/Edusp, 1971.

BAILLY, A; DEBARBIEUX, B. Géographie et représentations spatiales. In: BAILLY et alli.(coord.) Les concepts de la Géographie Humaine. Paris: Masson, 1995.

BONNEMAISON, J. Viagem em torno do território. In: CORRÊA; ROSENDAHL (coord.) Geografia Cultura: um século (3), Rio de Janeiro: Eduerj, 2002.

CLAVAL, Paul. A contribuição francesa ao desenvolvimento da abordagem cultural na Geografia. In: CORREAA, Roberto Lobato; ROSENDAHL, Zeny (Orgs.). Introdução à Geografia Cultural. Rio de Janeiro: Bertrand, Brasil, 2003. 
CORRÊA Aureanice. M. Irmandade da Boa Morte como manifestação cultural afro-brasileira: de cultura alternativa a inserção global. 2004. 323 f. Tese (Doutorado em Geografia) - Universidade Federal do Rio de Janeiro, CCMN/PPGG, Rio de Janeiro, 2004.

CORRÊA Aureanice. Não acredito em deuses que não saibam dançar: A festa do candomblé, território encarnador da cultura. In: Rosendahl, Z.; Corrêa, R. (org) Geografia: Temas sobre Cultura e Espaço. Rio de Janeiro: EdUERJ, 2005.

CORRÊA Aureanice. Território, Cultura e Transnacionalização de práticas culturais: a cultura afro-brasileira na Argentina. In: Pinon, M.; Coelho, M. C.; Corrêa, A. M. O Brasil, A América Latina e o Mundo: Espacialidades Contemporâneas II. Rio de Janeiro: Lamparina. ANPEGE; FAPERJ, 2008, v.2.

CORREAA Aureanice. O terreiro de candomblé: uma análise sob a perspectiva da geografia cultural. In: RevistaTextos Escolhidos de Cultura e Arte Populares, v.3, p.51 - 62, 2006.

CORRÊA Aureanice. Territorialidade e simbologia: o corpo como suporte sígnico, estratégia do processo identitário da Irmandade da boa Morte. Revista Brasileira de História das Religiões. v.1, p.121 - 133, 2008.

CORRÊA Aureanice. Festa da Irmandade da Boa Morte: a disputa pelo seu sentido. In: In: Rosendahl, Z.; Corrêa, R. (org) Espaço e Cultura: Pluralidade Temática. Rio de Janeiro. EdUerj, 2008, v.15.

CORRÊA Aureanice. O movimento de territorialização, a prática cultural afrobrasileira na África: um diálogo entre a Geografia e a Literatura. In:

Rosendahl, Z.; Corrêa, R. (org) Temas e Caminhos da Geografia Cultural. Rio de Janeiro :EdUERJ, 2010, v.19.

CORRÊA Aureanice. A "Caminhada Eu Tenho Fé" como prática cultural de afirmação de processos e respostas às ações de intolerância religiosa na cidade do Rio de Janeiro. In: Religiosidade Popular.Rio de Janeiro: UERJ/DECULT/FAPERJ, 2011.

CORRÊA Aureanice. O Sagrado é Divino, a Religião é dos Homens: Territórios Culturais e Fronteiras Simbólicas, a Intolerância Religiosa na Contemporaneidade. Revista Espaço e Cultura. v.1, p.125 - 138, 2012.

CORRÊA Aureanice. La carnavalización de lo sagrado: la fiesta de Iemanjá en Rio Vermelho. In: Territorios culturales y prácticas religiosas: nuevos escenarios en América Latina. Bahía Blanca: Editorial de la Universidad Nacional del Sur Ediuns, 2012.

CORRÊA Aureanice. Território santuário: uma via de operacionalização para a prática das religiões vinculadas à natureza. In: CORREA, A. M.; COSTA, L.; BARROS, J. F. P. (org.) A Floresta: Educação, Cultura e Justiça Ambiental. Rio de Janeiro: Garamond / FAPERJ, 2013. 
CORRÊA Aureanice. A cidade, a floresta e a criação do espaço sagrado em unidade de conservação: o caso da Curva do $S$ no Parque Nacional da Tijuca, na cidade do Rio de Janeiro In: Oliveira, F.; Freira, D.; Jesus, G.; Oliveira, L. (org.). Geografia Urbana: Ciência e Ação Política. $1^{\circ}$ ed.Rio de Janeiro - RJ Consequência Editora, 2014.

CORRÊA Aureanice. Geografia contemporânea, indagine sul terreno e territori culturalli. Confini semiografici fluidi: tra processi identitari e di alteritá. In: Revista Documenti Geografici, v.I . Roma, Universitá Roma Tor Vergata, 2014.

CORRÊA, Aureanice de M.; MELO, Emerson. Entre Fluxos e refluxos, agenciamentos territoriais e transnacionalização do Candomblé. In: Carballo, Cristina Teresa; Flores Fabián Flores (org.) Territórios, fiestas e paisages peregrinos: cartografias sociales de lo sagrado. Ed. Quilmes. La Imprenta digital, srl. Argentina. 2016.

CORRÊA, Aureanice de M. ; CORRÊA, Roberta. M. Territorialidades e transnacionalização da cultura afro-brasileira por meio da prática religiosa do Candomblé. In: Carballo, Cristina Teresa; Flores Fabián Flores (org.) Geografias de lo sagrado em la contemporaneidade. Ed. Bernal. Universidad de Quilmes, 2019.

CORREAA, Roberta. M. Bens entre mundos: fluxos de mercadorias sagradas e as esferas de legalidade/ilegalidade no Brasil e em Portugal. Apresentação de trabalho GT Direito, circulações e configurações territoriais. XII Congresso Luso-afro-brasileiro-CONLAB, Lisboa, 1/5 de fevereiro 2015.

CORRÊA, Roberta. M. The revival of religious intolerance:controversies surrounding the secular state in the scenario of the State of Rio de Janeiro. XII Congress Brazilian Studies Association. Londres, 20/23 agosto, 2014.

CUNHA, M. C. Negros, estrangeiros - os escravos libertos e sua volta à África. São Paulo: Brasiliense. 1985.

DEL PRIORI, Mary Del; VENANCIO, Renato P. Ancestrais: Uma Introdução à História da África Atlântica. Rio de Janeiro: Elsevier, 2004.

DI MÉO, G. L'Homme, la Société, l’Espace. Paris: ed. Econômica, col. Anthropos, 1991.

FRIGÉRIO, A. Umbanda e africanismo em Buenos Aires: duas etapas de um mesmo caminho religioso. Comunicações Iser, Rio de Janeiro, n.35,1990.

GILROY, Paul. O Atlântico Negro: modernidade e dupla consciência. São Paulo, Ed 34; Rio de Janeiro, Universidade Candido Mendes, Centros de Estudos Afro-Asiáticos, 2001.

GUATTARI, F.; ROLNIK, S. Cartografias do Desejo: Micropolíticas. Petrópolis: Vozes, 1986. 
GUATTARI, F. Espaço e Poder: a Criação de Territórios na cidade. Rio de Janeiro: In: Espaço e Debates, 1985.

GURAN, M. Os Agudás, os brasileiros do Benim. Rio de Janeiro: Nova Fronteira, 2000.

HALL, Stuart. Da diáspora: identidades e mediações culturais. Belo Horizonte: Ed. UFMG, 2003

LIMA, Vivaldo da C. A Família-de-Santo nos Candomblés Jeje-Nagôs da Bahia: um estudo de relações intra-grupais. $2^{\mathrm{a}}$ ed. Salvador: Corrupio, 2003

MAHLER, S. Theoretical and empirical contributions toward a research agenda for transnacionalism. In: Smith, M; Guarnizzo, (org) Transnacionalism from below. News Brunswick: Transaction,1998.

MATORY, J. L. Jeje: repensando nações e transnacionalismo. MANA [online]. 1999, vol.5, n.1, pp. 57-80.

MELO, Emerson. Entre territórios e terreiros: Yorubá, velhos deuses no Novo Mundo. 2014. 222 f. Dissertação (Mestrado em Geografia), - Universidade Federal de Minas Gerais, IGC/PPGG, Belo Horizonte, 2014.

PIERSON, D. Brancos e pretos na Bahia: estudo de contacto racial. São Paulo: Cia da Editora Nacional, 1971.

PORDEUS, I. Jr. Portugal em Transe: Transnacionalização das religiões Afrobrasileiras conversão e performances. Lisboa: ICS, 2009.

SACK, R. Human Territoriality: its theory and history. London: Cambridge University Press,1986.

SILVEIRA, Renato da. O Candomblé da Barroquinha: Processo de constituição do primeiro terreiro baiano de keto. Salvador: Edições Mainanga, 2006.

SODRÉ, M. O terreiro e a cidade. Petrópolis: Vozes, 1988.

SOPHER, D. Geography of religions. Engkood Cliffs, Prentice Hall Inc. 1967

VERGER, Pierre. Fluxo e refluxo do tráfico de escravos entre o Golfo do Benin e a Bahia de todos os Santos dos séculos XVII a XIX. Trad. Tasso Gadzanis. $4^{\mathrm{a}}$ ed. Salvador: Corrupio, 1987.

TINHORÃO, J. Os negros em Portugal. Uma presença silenciosa. Lisboa: Caminho, 1988. 